\title{
Aboriginal cultural educators teaching the teachers: mobilisng a collaborative cultural mentoring program to affect change
}

\section{Cathie Burgess $^{1}$ (D) $\cdot$ Valerie Harwood $^{1}$}

Received: 17 April 2020 / Accepted: 18 October 2021 / Published online: 4 December 2021

(C) The Author(s) 2021

\begin{abstract}
This paper discusses an Aboriginal cultural mentoring project for non-Aboriginal teachers that positions Aboriginal people front and centre as cultural and educational experts. In so doing it sets out to contribute to work in Australia that challenges 'common' understandings about mentoring in educational contexts where the expert is usually a western-educated non-Aboriginal teacher. In this project, nonAboriginal teachers are supported in implementing culturally responsive curriculum and pedagogies into their classroom through building relationships with Aboriginal mentors and students. Analysis of thirteen pre and post surveys, four mentee interviews and one mentee focus group, illuminated the emergence of collaborative cultural mentoring processes, where teachers developed trusting, reciprocal and respectful relationships with Aboriginal people. We argue that a systematic, wellsupported Aboriginal cultural mentoring program can be used to create and convert new knowledge into practice, and that this can have a positive impact on teachers' understanding of teaching/learning processes thereby contributing to Aboriginal student engagement in their learning.
\end{abstract}

Keywords Aboriginal $\cdot$ Mentoring $\cdot$ Teachers $\cdot$ Indigenous $\cdot$ Collaborative mentoring $\cdot$ Cultural competence

\section{Introduction}

This paper describes our analysis of how an Aboriginal community-led cultural mentoring program for non-Aboriginal teachers can increase teacher confidence in, and ability to, implement culturally responsive curriculum and pedagogy to better meet the educational, cultural and social needs of Aboriginal students. In this

Cathie Burgess

cathie.burgess@sydney.edu.au

1 University of Sydney, Camperdown, Australia 
program local Aboriginal cultural mentors modelled culturally responsive pedagogies (Author 1 et al.) for non-Aboriginal teachers to build relationships with Aboriginal families and improve their repertoire of skills in teaching Aboriginal students. What these pedagogies are, how these can be responsive and why they are significant for challenging non-Aboriginal mentees' learning experiences is discussed throughout this paper. This cultural mentoring approach as an example of professional learning was also designed to improve non-Aboriginal teachers' opportunities and skills in building relationships with local Aboriginal families and their children. As a number of researchers including Bond (2010), Craven et al. (2014) and Lowe et al. (2020) have argued, teachers building these skills are the key to improving Aboriginal student educational experiences, and as such is a major policy priority area at both state and federal levels (Gillan et al., 2017).

Importantly, this approach challenges deficit discourses about Aboriginal ${ }^{1}$ people and normalised assumptions of teacher as expert by positioning Aboriginal cultural educators (this terminology was agreed upon by the Aboriginal mentors) as mentors of non-Aboriginal teachers. This cultural mentoring program followed a three-day cultural immersion program in the local Aboriginal community, Connecting to Country (CTC), run by the Inner-City Aboriginal Education Consultative Group (AECG). An evaluation of the CTC program (Burgess \& Cavanagh, 2016) identified its impact in developing teachers' deep understanding of local Aboriginal families and communities and connecting with local culture to implement culturally responsive curriculum and pedagogies with a view to engaging Aboriginal students in their learning. Such positive impact has been reported in similar teacher professional learning programs where Aboriginal cultural educators work with teachers to improve their confidence and efficacy in teaching Aboriginal children (cf Bishop et al., 2019; Craven et al., 2014; Harrison et al., 2016; Yunkaporta \& McGinty, 2009).

Yet, a key issue arises when, after the CTC program, teachers lacked the time and support needed to confidently implement their new knowledges and skills (Ma Rhea, 2015) into their daily teaching practices. The cultural mentoring program provided one approach to investigate how this key issue of teachers implementing new knowledge and skills might be addressed. The purpose of the cultural mentoring program was to build on teachers' professional learning from the CTC program and to help them maintain the motivation to develop culturally responsive teaching practices and integrate Aboriginal community-informed content into their lessons. In this paper we argue that a systematic, well-supported and sustainable program of cultural mentoring by local Aboriginal community members can significantly impact teachers' understanding of teaching/learning processes to improve Aboriginal student engagement in their learning.

\footnotetext{
1 The term," Aboriginal," is used because the research it describes was conducted on Aboriginal (Gadigal) land and acknowledges that the Aboriginal participants are from many nations across NSW.
} 


\section{Researcher positionality}

Cathie Burgess is a non-Aboriginal educator who has worked in Aboriginal education for over 35 years as well as a parent of Aboriginal children involved in local Aboriginal community sports where this project is situated. Valerie Harwood is a non-Aboriginal woman who was born on Kaurna Country and whose research focusses on educational disadvantage and how this affects Aboriginal students and communities. We are non-Aboriginal academics/researchers committed to reshaping power relationships through collaborating with local Aboriginal communities to improve Aboriginal student learning experiences, community engagement and teacher effectiveness. Our local place-based methodological and pedagogical approaches include learning from Gadigal and Yuin (NSW South Coast) Elders and community members to address these challenges. We are aware of our white privilege and cultural biases and so are guided by Aboriginal family, colleagues, and friends in this lifelong commitment to social justice. Positioning ourselves in research contexts is important as it acknowledges the power dynamics inherent in research settings (Shay, 2019) and notes how participants engage subject positions to narratively construct their identity within specific contexts. We acknowledge that Aboriginal sovereignty has never been ceded and as we work on Gadigal land, we believe that this 'place' should be the focus of our efforts to reshape power relations.

The next section provides the context of this program, which is located in the Australian and Indigenous education setting, followed by an overview of key mentoring literature in teacher professional learning. This focusses on mentoring in Indigenous contexts, revealing gaps in the literature, particularly in research studies where Indigenous people mentor and/or lead non-Indigenous teacher professional learning.

\section{Context}

The ongoing educational disadvantage of Australian Aboriginal students is well documented in government reports and academic research (cf Bodkin-Andrews \& Carlson, 2014; Buxton, 2017; Gillan et al., 2017). Initiatives designed to alleviate disadvantage such as the federal government's Close the Gap strategy are having minimal impact and sometimes aggravate this through the accompanying disempowerment of Aboriginal communities (Buxton, 2017). The recent Closing the Gap in Partnership agreement between federal and state governments and the Coalition of Peaks signals the need for partnerships with Aboriginal communities and Aboriginal Community Controlled organisations (Commonwealth of Australia, 2020). Despite commitment from individual teachers and political and systemic support to improve Aboriginal student outcomes, the disparity in achievement rates appears entrenched and difficult to shift.

Quality teachers and teaching are widely regarded as key determinants in improving students' educational outcomes (Hattie, 2009; Naylor \& Sayed, 2014). In the seminal research study on quality teaching, Ladwig et al. (2009) noted that when students were given high quality assessment tasks, Aboriginal student achievement 
exceeded that of all students, thus reducing the outcome gap between Aboriginal and non-Aboriginal students. In multicultural contexts, high quality teaching includes skills beyond academia such as understanding their students' out-of-school-lives and affirming their cultural identity, building relationships with parents and community members, and understanding the specific historical, political, and societal contexts impacting on Aboriginal lives (Lowe et al., 2019a). Specific ongoing professional learning is necessary for developing these skills, and cultural immersion experiences are increasingly recognised as effective, (Harrison et al., 2016; Vass et al., 2019). In a systematic review (2006-2017) analysing teacher professional learning designed to support Indigenous students, Vass et al. (2019) noted significant gaps in the literature such as a lack of conceptual and/or theoretical frameworks to contextualise and compare studies, little information on the impact of context and relational processes, poor attention to power hierarchies and institutional racism, an absence of community voices, and little evidence to connect specific professional learning to improved Aboriginal student outcomes. The findings from this project suggest that the Aboriginal-led and designed nature of the teacher professional learning experiences highlight the importance of issues such as context, relationality, power relations and community voice.

With an increasing concern about the need for teachers to understand and respect the cultural backgrounds of Indigenous students (Lowe et al., 2019a), teacher professional learning models that focus on cross-cultural competency are in demand (Sinclair, 2020). Across diverse Indigenous Australian contexts (such as urban, rural, remote), very few culturally-based teacher professional learning programs exist (cf, Bainbridge et al., 2014; Burgess et al., 2020; Harrison, et al., 2016; Yunkaporta \& McGinty, 2009) even though there is a growing acknowledgement that "Aboriginal ways of seeing, knowing and being should be at the forefront of any professional learning for school leaders and classroom teachers" (Buxton, 2017, p. 198). Vass et al., (2019) further note the need for more research on teacher professional learning which impacts positively on Aboriginal student experiences. The findings from this study respond to this need by analysing the impact of Aboriginal-led teacher professional learning through an intensive, relationships-focussed Aboriginal cultural mentoring program for teachers.

\section{Mentoring in teacher professional learning}

Teacher professional learning programs are, it seems, yet to embrace the importance of Indigenous designed culturally based programs, with the result that there is limited availability, there is inadequate funding to engage community, and funding is rarely made sustainably available on an ongoing basis (Bainbridge et al., 2014; Craven et al., 2014; Vass et al., 2019). This lack of sustained engagement by teacher professional learning programs in Indigenous led culturally based mentoring programs means that there is relatively limited Australian based literature on this form of specialised mentoring for teachers. 
Unsurprisingly, there is a gap in the literature on this important area of teacher professional learning. Significantly, the notion of Aboriginal educators mentoring non-Aboriginal educators (as is the basis of this project) appears to be relatively rare, at least in published academic literature. Published reports of projects tend to focus on the mentoring $O F$ Aboriginal people $B Y$ non-Aboriginal people (cf, McMahon et al., 2017; Ware, 2013). While we are not pejoratively taking up issue with all of this work, we do have an issue with this dominance and the dearth of published work on the important and significant mentoring that Aboriginal people have and continue to offer to, non-Aboriginal people.

In this paper we partially address this gap by considering mentoring as a professional learning experience to improve teacher effectiveness; however, in so doing we state that we recognise the mentoring that Aboriginal people have given and continue to give to non-Aboriginal people, ourselves included. In considering mentoring by Aboriginal people of non-Aboriginal people Bainbridge et al. (2014) note that differences between Indigenous and non-Indigenous epistemology, ontology and axiology are likely to result in dissonance in mentoring expectations, processes and outcomes. These authors make the point that "in contemplating mentoring work with Indigenous Australians, acknowledging Indigeneity as a particularly important consideration [is required] because at its heart are strong value-based connections that are shared in the ensuing relationships" (Bainridge et al., 2014, p. 2). This dissonance can undermine mentoring processes, and for this reason the importance of prioritising the Indigenous voice in developing and designing mentoring programs cannot be understated.

The value of Indigenous mentoring of non-Indigenous teachers is demonstrated in the Te Kotahitanga educational reform project in Aotearoa/New Zealand. This project improved Maori student participation and achievement (Bishop et al., 2014a) through a culturally responsible mentoring program where Te Kotahitanga facilitators worked with science teachers to develop culturally sustaining science instruction for Maori students (Tolbert, 2015). Drawing on Zozakiewicz's (2010) "culturally responsible mentoring" model that identifies culturally responsible teachers as those who make conscientious and responsible decisions to support diverse students and their families, Tolbert (2015) notes that this approach helps teachers develop culturally responsive pedagogies and relationships with Maori students to effect change. Bishop et al., (2014b) also note that "the in-school facilitators (mentors) helped teachers understand how they could bring about change in their classroom practice and develop caring and learning relationships within responsive social contexts" (p. 53). Bishop et al., (2014b) study is significant as it demonstrates evidencebased connections between culturally responsive mentoring and improvements in Māori student outcomes. Importantly, both Zozakiewicz (2010) and Tolbert (2015) concluded that mentoring needs to be improved or teachers will continue to struggle with teaching diverse students and that more research is needed on culturally based professional learning for teachers.

While the premise of this project is Aboriginal cultural educators mentoring nonAboriginal teachers, the collaborative mentoring approach developed organically as Aboriginal and non-Aboriginal participants worked together to design project-based learning for the students. The value of this approach can be articulated by drawing on 
studies by Kemmis et al. (2014) and Cuddapah and Clayton (2011) which described mentoring as enacted as a collaborative peer group endeavour facilitated by an experienced teacher to support new teachers in developing co-mentoring relationships (p. 161). As Cuddapah and Clayton (2011) noted, "the cohort was more than just a strong community where emotions were shared; it became a purposeful place for peer mentoring where new teachers affirmed each other, made sense of their experiences, and shared practices" (p. 71). While there are differences between these studies and the project that we are describing, here we draw attention to work that acknowledges the benefits of experienced mentors such as the Aboriginal cultural mentors, building collaborative mentoring with non-Aboriginal teachers.

The benefits of collaborative mentoring extend to the potential for addressing issues of racism and power hierarchies. In line with findings from Vass et al. (2019) regarding a lack of acknowledgement of the power hierarchies often visible in Indigenous professional learning programs, Lopez (2013) found that 'race', racism and whiteness were sources of tension for teachers and so developed a collaborative mentoring program to improve teachers' understanding and management of complex racialised and ethnic differences through critical self-reflection.

\section{Method}

This paper analyses teacher mentee experiences in the cultural mentoring program to extrapolate what they learnt about Aboriginal cultures and histories, relationship building with Aboriginal people and how to better engage Aboriginal students in their learning. It forms part of a larger study that also includes the experiences and perceptions of the mentors (Aboriginal cultural educators). While mentors' voices are beyond the scope of this paper, they will be foregrounded in future works. A case study approach (Harrison et al., 2017) was taken guided by Indigenous research principles (Lincoln et al., 2008; Smith, 2012) and what Murray and Harwood (2016) term Aboriginal Australian Research Protocols, which emphasise "respect, relationship and rights to knowledge" (Harwood \& Murray, 2019, p.17). Attention to these principles and protocols was applied where Aboriginal community members and cultural mentors guided the shape of the mentoring project in discussions held prior to the start of the project.

We conducted interviews and focus groups at the site where the cultural mentoring project was implemented. The site selected is located in a high density, multicultural, inner-city suburb of Sydney, Australia, the site of initial invasion and subsequently a place renowned for political activism in the struggle for social justice for Aboriginal people. This is Gadigal land and the local Aboriginal community for the two schools is located here, and so the socio-political context where many Aboriginal community members are long-term activists influences this study.

\section{Participants}

A targeted group of early career and/or recently appointed non-Aboriginal teachers at a K-12 community school and nearby behaviour school were chosen by each 
school's executive. Thirteen non-Aboriginal teachers (mentees) and four Aboriginal cultural educators (mentors), participated in the CTC program consisting of culturally significant site visits, yarning sessions with Elders, parents and students, and local Aboriginal agency visits. Factors such as which teachers were eligible for the program, how many Aboriginal people were available to participate in the program and what Aboriginal community sites were available for use in the program were all key considerations in developing the project. The cultural mentoring program followed this, and each teacher received two hours cultural mentoring per week for eight weeks. Guidance from the local Aboriginal community and cultural mentors identified mentor/mentee partnerships, and factors such as gender, teaching area and expertise (Ware, 2013) were considered. Aboriginal community members and cultural mentors involved in the program were remunerated for their time and expertise. Together, mentors and mentees discussed how the mentoring process might work such as classroom observations, problem-based learning, project-based activities and reflective dialogue. Subsequently, all partnerships developed a project-based, dialogic approach where the students as well as the mentees and mentors played an active role in the teaching and learning process.

\section{Data collection}

Data from pre and post program surveys, interviews and focus groups were collected on the perceptions, experiences and impacts of the cultural mentoring program on the teacher mentees. This consisted of 13 pre and post program surveys $(100 \%$ response rate), four mentor interviews, four mentee interviews and one mentee focus group. For the purposes of this paper, only teacher mentee surveys, interviews and focus groups were analysed. The surveys consisted of Likert-style and open-ended questions to elicit quantitative and qualitative data that were triangulated with interviews and focus groups. Interviews and focus groups employed yarning, a commonly applied approach in Indigenous methodology to provide participants with opportunities to story their experiences (Bessarab \& Ng'anda, 2010; Shay, 2019) in ways that best expressed their understandings of the project, rather than feeling constricted by the guiding questions. This allowed opportunities for narrative descriptions of experiences that go beyond the question and capture the full breadth and nuances of the experiences in a culturally respectful manner. Analysis was conducted in coding software NVivo firstly to consider the interview questions and then an organic approach was applied to examine and aggregate individual responses into common themes.

Human Research Ethics approval was secured with The University of Sydney (2014/872) and the NSW Department of Education and Communities (SERAP 2014255), and pseudonyms are used to protect confidentiality. Credibility was established by foregrounding Indigenous protocols for listening to and learning from Aboriginal people (Shay, 2019) and modelling this for non-Aboriginal participants to consolidate their understanding of culturally responsive practices (Burgess et al., 2020). This also acknowledges the Aboriginal land the project occurred on, as Moodie (2018) notes, "(this) centres place and relationality of place as core concepts 
in Indigenous education research" (p. 38). Furthermore, the data were triangulated across the surveys, interviews and focus groups to further enhance credibility

\section{Key findings}

In this section we map out our findings in terms of three key areas. The first is Teacher Learning and New Knowledge and Skills where we note in particular the Cultural mentoring programs supporting the development of collaborative projectbuilding, and the development of relationships. The second key area is Teacher Learning of the Cultural Mentoring Process. Here we note the impact on self-positioning; cultural literacy; understanding the historical, socio-cultural and political context. The third key area that was identified is the Impact of Mentoring on the Teachers. Our analysis also identified the barriers to the program.

"(I)t was actually a team process, it was all of us learning together."

In the above statement Kate (mentee) aptly describes the overall experience of being mentored by the Aboriginal cultural mentors for the teacher participants. Kate's statement helps us to appreciate the experience the mentors created for the teachers, an experience of a team, of "us learning together". We begin this section with Kate's statement to draw attention to both the positive responses that the teachers provided and to highlight the mentoring environment that the Aboriginal mentors developed with the non-Aboriginal teachers. It highlights how this program provides a unique professional learning experience for teacher mentees. This section presents the teacher mentee comments about their experiences of the mentoring process and their descriptions of the impact this had on their professional and personal lives. The discussion is organised into three themes: (i) Teacher learning-new knowledge and skills; (ii) Teacher learning-the cultural mentoring process; and (iii) The impact of mentoring. The first two themes are grouped under aspects of teacher learning such as collaborative project building, relationships, self-positioning, cultural literacy, understanding the historical, and socio-cultural political context. The third theme analyses the impact of the project including any barriers that the teachers described experiencing.

\section{(i) Teacher learning—new knowledge and skills}

The 'how' the learning occurred, rather than the 'what', significantly impacted the teachers. That is, the processes involved in the learning with the Aboriginal mentors impacted the teachers. This impact included learning experiences that the teachers hadn't previously been exposed to either in their undergraduate degrees or during inservice professional learning. In this sense, the teachers in this mentoring program reported new experiences of processes learning because of their involvement in the mentoring with the Aboriginal mentors. 


\section{Collaborative project-building}

Aboriginal cultural mentors and teacher-mentees approached the mentoring process by co-designing a practical project that involved the students. The overwhelming majority (92\%) of participants believed that this would provide a more appealing experiential learning approach to engage their students. This dialogic, 'hands-on' approach reflects Aboriginal ways of interacting and relationshipbuilding, forming a focal point for teacher learning (Burgess et al., 2020). As pedagogy was grounded in classroom practice, multi-dimensional communication and interpersonal relations, an exchange of ideas built on difficult knowledges, and commitment to the process was more important than finding solutions (Lefstein \& Snell, 2014).

This occurred, for instance, in the mentoring activity of preparing their school students for a public speaking competition. Difficult historical and cultural knowledge was attended to by the mentee teachers, for example, by challenging Aboriginal students' use of the word 'shame' to express their embarrassment about possible failure. In the interview excerpt below Kate (a teacher mentee) explained,

Mia (mentor) discussed the foundations of 'shame'. She told them that shame is a white concept, it's been put on Aboriginal people to make them ashamed of who they are and ashamed of their culture. Therefore, every time you say that, you're giving power to white people and you're taking power away from yourself. And it's stopping you moving forward. (Kate, Teacher Mentee)

Aboriginal student use of this term was challenged by Mia (mentor), so that students could consider deeper understandings of the impact of coloniality on their thinking and so move on to developing the necessary public speaking skills. This can be a common pattern in Aboriginal student thinking, an observation noted in the Australian Indigenous Mentoring Experience (McKnight et al., 2018), which devised similar strategies to address this issue. For Kate, it also meant that she could continue this dialogue with students after the mentoring program, thus encouraging her and the students to embrace difficult, but critical conversations. What is important to note here, is that while similar strategies are reported in other scholarship, here we are describing critically important learning for mentee teachers, learning that they had not previously experienced. Involvement in this mentoring program, then, had produced an experience of learning that directly and positively impacted Kate's teaching with her students in ways that had not occurred in her undergraduate teaching degree or in other professional learning experiences.

In another project, Phillip (mentor) taught Rick (mentee) and the students how to 'read' the school environment through an Aboriginal lens to create an environmentally sustainable edible garden based on each student's cultural background.

(we have) a lot of native flora, and it was good to take him (Phillip) around to see this because he said ... oh in this space you could do this ... and then we took some of these ideas and started a garden creating a New South Wales map of the Aboriginal language groups so the students could show where they came from. (Rick, mentee) 
By linking environmental knowledge to student's Country, a sense of belonging and connectedness emerges (Harrison et al., 2016) demonstrating for Rick, the power of supporting identity and culture in engaging students. Lowe et al. (2020) note the significance of place-based learning on Country to increasing cultural inclusion within the school particularly when these initiatives are driven by local community members (p. 8).

\section{Relationships}

Relationship building has long been acknowledged as key to engaging Indigenous students in their learning (Bishop et al., 2014b; Burgess et al., 2019). In this project, the mentees, Linda, Kate, Anna and Rick noted that learning from the Aboriginal cultural mentors, Mia, Sarah, Phillip and Joan, occurred through observing and participating in relationship building processes and activities. As Linda (mentee) explained,

I was watching how she was interacting with the kids... that for me was the most valuable piece of the whole thing ... how she was speaking to them explicitly, questioning them, ... the kids really get it .... and she kind of goes around it so if they're off task and they're doing something else she brings them back around and gets them to tell their own stories. (Linda, mentee)

This circumlocutive communication style of talking around an issue before getting to the point (Bessarab \& Ng'andu, 2010) was used by mentors to engage with the students, demonstrating for the teacher mentees, culturally appropriate ways of working with students (Bishop et al., 2014a). Anna noted that this was in contrast to key principles about personal and professional boundaries that she had learnt in university and was surprised at how her mentor, Joan, was able to maintain respect and control while informally yarning with students.

I noticed the first thing when she came into the class, she sat down very informal with me and the kids, and was telling stories about herself, and I noticed straight away the importance of that informality ... chatting, getting to know one another, finding out their values and what's really important to them. (Anna, mentee)

Another mentee Linda, noted that respectful relationships were developing in her classroom, by noting that "they're (the students) witnessing our relationship and developing theirs with Sarah ... witnessing an Aboriginal person as an expert ... "cause it's too often the other way around". This comment indicated Linda's growing level of conscientisation (Gay, 2010) in acknowledging her mentor's expertise and the importance of including the school students in the curriculum development process. These observations acknowledge a critical shift in power that counteracts deficit discourses often applied to Aboriginal people (Burgess et al., 2020).

Learning from the Aboriginal cultural mentors about the value of leveraging personal and familial knowledge and experiences to build relationships with students was successfully enacted by Rick (mentee) during the cultural mentoring program, 
"I was telling the kids the process while we were working and talking, telling them about how my grandfather and dad would make it (family recipe) and then take it around to all our family". Connecting with his students through sharing personal cultural history built belonging, shared experience and trust, crucial to engaging students in their learning.

\section{(ii) Teacher learning - the cultural mentoring process}

Key learnings for the teacher-mentees centred around understanding the importance of locating oneself in the social world, knowledge and understanding of culture and cultural processes, and understanding the socio-cultural historical and political context of the local Aboriginal school community.

\section{Self-positioning}

For Aboriginal people, positioning oneself is an important cultural protocol to locate each other geographically, politically and genealogically. This occurs through greetings such as "who's your mob", "where you from" in order to position themselves and others in the relational world of family, kin, cultural/language group and/or Country/nation (Bessarab \& Ng'anda, 2010). Aboriginal students will often use this approach with their teacher (regardless of background) to determine relational positioning and test potential levels of trust. Anna (mentee) observed this when her mentor introduced herself to the class through family connections, noting that, "family is definitely important to everyone ... telling me all about her cousins and aunties ... I noticed that it was a big thing for Aboriginal students I have in my class". These conversations are very important to Aboriginal students and teacher responses to this relational positioning is crucial if they are to build trust relationships with their Aboriginal students. Linda (mentee) explained;

I really value storytelling and understanding where people come from ... I love knowing their stories in terms of understanding the way different people learn ... once you have a relationship with a kid, they're going to want to tell you all about their lives.

For many of the teachers, this new way of knowing, being and doing through the narrative constructs of yarning and positioning (Bessarab \& Ng'andu, 2010), challenged their persona as expert and reconceptualised classroom relationships. Engaging in critical self-reflection on personal positioning (Gay, 2010) was identified by Kate (mentee) as "understanding personal cultural identity ... relationship to teaching ... being aware of your own privilege is instrumental ... looking at the place that the kids start from and therefore how that's so different from the place that I started from". This assisted her in developing a deeper understanding of Aboriginal students and their families and motivated her to mobilise strategies to address equity issues. 


\section{Cultural literacy}

Poor cultural literacy among the general teaching population is often noted by Aboriginal parents in key research reports (Burgess \& Cavanagh, 2016; Gillan et al., 2017; Lowe et al., 2019b). In this study, $85 \%$ of teachers reported some understanding of Aboriginal culture and history through their university studies but noted that real learning is experienced first-hand. A number of participants indicated that the cultural mentoring program gave them that first-hand knowledge of local history through listening to and learning from Aboriginal people, as Rick (mentee) said; "that's where the culture is. It's out on the land, underneath the sky, the sun and the stars ... that's how I feel, to learn about Aboriginal culture you've just got to be out on the land". Anna (mentee) also noted the importance of learning from Aboriginal people, "when you're talking culture, I wouldn't even know what questions to ask ... but you have to be told and listen to the stories. That's how lots of people, including Aboriginal people, share culture, teaching and telling stories". She explained how cultural mentoring provided her with guidance when interacting with Aboriginal people. "She (Sarah, mentor) gave me feedback in terms of my body language. Do I look welcoming? Am I communicating properly so that parents feel they can talk to me ... then I can build rapport and trust from that" (Anna, mentee).

Studies have reported that Aboriginal parents are concerned about the lack of accuracy and authenticity of available information on Aboriginal history and culture (Burgess \& Cavanagh, 2016), and teachers hesitate to include this in their programs due to their own lack of knowledge and education in this area and often fear doing the wrong thing (Baynes, 2016). This lack of knowledge was depicted in Linda's (mentee) comment below and so she recognised the value her mentor's advice here, "you would try and research on the internet, and while the information is out there ... she was telling me different things from what I was planning to teach to the kids. So that definitely stood out for me".

The importance of local, embodied knowledge was also a key learning experience (Harrison et al., 2016) noted by many mentees such Rick (mentee) who stated; "I'm not from this area and for me to find out how much Aboriginal culture is in this area was eye-opening "cause I thought it was all in rural areas". The notion that Aboriginal culture exists in the city is reinforced through neo-colonial discourses of real-Aborigines living in remote Australia therefore denying urban-based Aboriginal peoples' claims of authenticity (Bodkin-Andrews \& Carlson, 2014; Fredericks, 2013). This stereotype is so prevalent that Rick (mentee) felt it necessary to explicitly state otherwise; "there's culture right here in the city ... mainstream society doesn't realise but it's really important to these kids, even if they don't come from here, the fact that they live here makes it really important".

\section{Understanding the historical, socio-cultural and political context}

Aboriginal parents and community members often reiterate the importance of teachers understanding their local historical, cultural and political community context (Burgess \& Cavanagh, 2016; Lowe et al., 2019a) in order to better understand their children as well as provide a culturally responsive curriculum. Here, teachers were 
often surprised at the breadth and depth of history and culture in the community and the extent to which the community continually engages with the political struggle. Anna (mentee) explained;

it was new and inspiring experience that demonstrated the value of the Aboriginal-land relationship and local Aboriginal peoples' commitment to and persistence in fighting for their rights ... just to see that people are working so hard and going to such lengths to have a voice and bring the community out into the broader Australia ... that was powerful for me.

Moreover, $77 \%$ of the teachers who participated in the cultural mentoring program believed that the experience changed their perceptions and understandings about Aboriginal people and culture in an urban environment. In particular, there was an increased understanding of the positive attributes of Aboriginal culture and the community and acknowledging this in their teaching.

\section{(iii) Impact of mentoring on the teachers}

A key impact of the program on teachers was increased confidence in building relationships with the Aboriginal community through their Aboriginal cultural mentor who was also a community member. As such, the mentor shared community protocols and information that further supported opportunities to engage with Aboriginal families. Improved relationships with students also followed as mentees, mentors and students worked together on their projects on Aboriginal topics that were highly engaging for the students. An example of how the mentoring program impacted teacher's understanding of Aboriginal students can be seen in Anna's (mentee), comment below about the stereotypes that she had acquired about Aboriginal students when she was at school, and how these changed as a result of the program;

I went to a high school where they prided themselves on being Aboriginal ... but it manifested more as the Aboriginal kids getting to use the phone in the office when no-one else was allowed to ... there was resentment about kids getting special treatment ... (but) now see why and I can see the fairness of it.

This reveals an emerging conscientisation (Gay, 2010) through building relationships with Aboriginal people that can change perspectives, address misconceptions and build confidence as Anna (mentee) noted, "you have your mentor to get you to that stage where you feel more equipped and confident, and you take that confidence into the classroom". Moreover, as a result of this increased confidence, some teachers noted a sense of responsibility and obligation to educating others as Linda (mentee) explained, "being able to speak to other people about what I've learned and educate them. There are so many misconceptions and wrong views of what the history is, being able to have constructive conversations is satisfying".

The importance of consulting with Aboriginal parents and communities in order to develop productive relationships is well supported (Lowe et al., 2019a; Yunkaporta \& McGinty, 2009), so it is not surprising that mentees viewed this as significant to their teaching. Kate enacted this by focussing on what her students could do 
rather than couldn't do, and this became the key to developing reciprocal trust relationships with families and students; "I called one parent and said, 'your son did his speech and while he only did it to me instead of the whole class, he spoke clearly' ... they were so happy to hear that" (Kate, mentee). Again, this demonstrates a critical shift away from deficit thinking to consciously enacting a more positive and supportive approach, therefore providing opportunities for improved engagement of Aboriginal families and students in schools.

\section{Barriers}

Despite the overall reported success of the program, individual and organisational barriers were identified as limiting the long-term impact of the program. Barriers such as these are not a typical of many professional learning programs in Aboriginal education, where short-term, one-off programs are implemented and later abandoned when funding and/or resources are no longer available (Vass et al., 2019).

Individual factors tended to focus on how secure and/or comfortable the mentee felt about being mentored, as Anna (mentee) suggested; "I think probably one barrier was my personal resistance to mentoring". She explained that she was not comfortable with the idea of mentoring, reflecting her perception of mentoring as supervision rather than a collaborative process (Devos, 2010), indicating a need to engage in new ways of thinking about how mentoring can be enacted.

Structural and organisational issues also presented significant challenges. All of the Aboriginal cultural mentors were employed elsewhere, and each was either paid if the activities occurred outside their work hours and/or provided with workplace relief to attend the mentoring activities. However, this is unlikely to be sustainable over a longer period of time. Further, identifying Aboriginal cultural mentors who are confident in working in a school environment is challenging, given factors such as availability, personal experiences with schools and confidence in teaching/learning processes (Lowe et al., 2019a, b).

Teachers also noted that an ever growing list of administrative tasks (Sinclair, 2020) made it challenging to accommodate the weekly mentoring meetings as Kate (mentee) lamented, "it got hard towards the end of term, "cause I just had no time to sleep let alone have a mentoring meeting". Teachers often felt distracted by these pressures, disappointed that they couldn't always give their full attention to the project and that it was only for a short period of time. To some degree, these barriers undermine the positive outcomes of the program and raise more issues than can be addressed here.

\section{Discussion}

The cultural mentoring program highlighted the effectiveness of Aboriginal cultural experts in teaching the teachers involved in this study about local Aboriginal cultures, histories and issues. Importantly, the cultural mentoring program has assisted in preparing them for developing reciprocal relationships with Aboriginal parents, 
students and community members, and learning to become more effective teachers of Aboriginal students (Lowe et al., 2020).

Aboriginal mentors modelled culturally responsible mentoring (Tolbert, 2015) by designing project-based activities that were inclusive, informative, and engaging. These activities were based on new knowledge drawn from mentor's cultural experiences and local Aboriginal cultural sites and was shared in culturally responsive and collaborative ways. A number of mentees articulated that learning by observing ways in which their Aboriginal cultural mentor interacted with the students, positively impacted their personal and professional identity and confidence in accessing and applying Aboriginal knowledges and skills to achieve a culturally responsive and inclusive classroom (Burgess et al., 2020).

Collaborative mentoring was substantially used throughout the program as Mia (mentor) noted; "it's not that one person is the expert and the other person isn't. It's not an instructional thing but a collaborative project building thing". This sense of collaborative project building reflects Aboriginal protocols as well as the sense of collegiality that generally exists within the teaching profession. Moreover, as this two-way collaborative teaching and learning process is founded on a strength-based approach that mobilises community cultural wealth (Yosso, 2005), this highlights the conceptual significance of this approach to teacher professional learning. Many mentees noted the significance of Aboriginal people positioned as experts in terms of challenging deficit discourses, misconceptions and ignorance, and they applied skills in addressing these usefully beyond their professional work and into their personal lives. The dialogical relational approach that emerged through this project, supported the development of mentees' critical consciousness (Gay, 2010) and inspiration to effect change in their classrooms.

This project demonstrated how the difficulty, fear, and antipathy that many teachers display when being prompted to work with Aboriginal students and their families could be addressed through professional approaches such as this program where genuine engagement with Aboriginal community members as leaders is central to program design. As the Aboriginal cultural mentors are also community members, they were able to help teacher mentees understand the importance of, and how to build, respectful and reciprocal relationships with Aboriginal people and utilise these skills in developing more engaging classrooms for Aboriginal students. As relationships developed through the cultural mentoring program, teacher mentee confidence and agency improved and there was a general sense of optimism for improving the educational experiences of their students.

\section{Conclusion}

We suggest that this Aboriginal cultural mentoring program differs from much of the more mainstream literature on Indigenous or minority mentoring projects because in this project Indigenous people (minority) were doing the mentoring, rather than being mentored (Bainbridge et al., 2014). We also have maintained that this approach connects with efforts to situate a shift in power, agency, and mentoring discourses away from those who, we argue erroneously, all too often claim 
expertise. As such, this paper goes some way to contributing to discourses that challenge 'common' understandings about what mentoring and indeed teaching 'is' and the critical importance of building opportunities for sustainable mentoring programs for non-Aboriginal teachers that are led by Aboriginal people.

Building collaborative relationships through the cultural mentoring program provided opportunities for more in-depth understanding of Aboriginal ways of knowing, being and doing, that in turn, teachers could embed in their curriculum and pedagogy. Moreover, it was clear from mentee interviews that they critically reflected on their experiences in terms of how to improve their teaching practice through rethinking, reconceptualising and recontextualising their daily teaching practice.

While limited by the short-term nature of the project, this paper points to the demonstrable potential that a sustained approach to Aboriginal mentors mentoring non-Aboriginal people could offer to improve the landscape in teacher professional learning in Aboriginal education; potential that could be realised through a long term, sustainable approach to teacher professional learning (Lowe et al., 2020).

The recurrent theme in this project is that teacher mentees valued the lessons they learnt from their mentors for engaging Aboriginal students in their learning, and developing a deeper appreciation of the significance of place-based learning led by local Aboriginal experts. Moreover, as Aboriginal cultural mentors and teacher mentees found that their common purpose of improving Aboriginal student outcomes superseded previously perceived boundaries of difference, dissonance and disconnection, relationships flourished, and real learning began.

Open Access This article is licensed under a Creative Commons Attribution 4.0 International License, which permits use, sharing, adaptation, distribution and reproduction in any medium or format, as long as you give appropriate credit to the original author(s) and the source, provide a link to the Creative Commons licence, and indicate if changes were made. The images or other third party material in this article are included in the article's Creative Commons licence, unless indicated otherwise in a credit line to the material. If material is not included in the article's Creative Commons licence and your intended use is not permitted by statutory regulation or exceeds the permitted use, you will need to obtain permission directly from the copyright holder. To view a copy of this licence, visit http://creativecommons.org/licen ses/by/4.0/.

\section{References}

Bainbridge, R., Tsey, K., McCalman, J., \& Towle, S. (2014). The quantity, quality and characteristics of aboriginal and Torres Strait islander Australian mentoring literature: A systematic review. BMC Public Health, 14(1263), 1-25.

Baynes, R. (2016). Teachers' attitudes to including Indigenous knowledges in the Australian science curriculum. The Australian Journal of Indigenous Education, 45(1), 80-90.

Bessarab, D., \& Ng'andu, B. (2010). Yarning about yarning as a legitimate method in Indigenous research. International Journal of Critical Indigenous Studies, 3(1), 37-50.

Bishop, M., Vass, G., \& Thompson, K. (2019). Decolonising schooling practices through relationality and reciprocity: Embedding local Aboriginal perspectives in the classroom. Pedagogy, Culture \& Society. https://doi.org/10.1080/14681366.2019.1704844

Bishop, R., Berryman, M., \& Wearmouth, J. (2014a). Te Kotahitanga: Towards effective education reform for indigenous and other minoritised students. New Zealand Council for Education Research Press. 
Bishop, R., Ladwig, J., \& Berryman, M. (2014b). The centrality of relationships for pedagogy: The Whanaungatanga Thesis. American Educational Research Journal, 51(1), 184-214.

Bodkin-Andrews, G., \& Carlson, B. (2014). The legacy of racism and Indigenous Australian identity within education. Race Ethnicity and Education, 19(4), 784-807.

Bond, H. (2010). 'We're the mob you should be listening to': Aboriginal elders at Mornington Island speak up about productive relationships with visiting teachers. Australian Journal of Indigenous Education, 39(1), 40-53.

Burgess, C., Bishop, M., \& Lowe, K. (2020). Decolonising Indigenous education. The case for cultural mentoring in supporting Indigenous knowledge reproduction. Discourse: the Cultural Politics of Education. https://doi.org/10.1080/01596306.2020.1774513

Burgess, C., \& Cavanagh, P. (2016). Cultural immersion: Developing a community of practice of teachers and Aboriginal community members. The Australian Journal of Indigenous Education, 45(1), 48-55.

Burgess, C., Tennent, C., Vass, G., Guenther, J., Lowe, K., \& Moodie, N. (2019). A systematic review of pedagogies that support, engage and improve the educational outcomes of Aboriginal students. Australian Educational Researcher, 46(2), 297-318.

Buxton, L. (2017). Ditching deficit thinking: Changing to a culture of high expectations. Issues in Educational Research, 27(2), 198-214.

Commonwealth of Australia, Department of the Prime Minister and Cabinet, (2020). National Agreement on Closing the Gap. Author

Craven, R. G., Yeung, A. S., \& Han, F. (2014). The impact of professional development and Indigenous education officers on Australian teachers' Indigenous teaching and learning. Australian Journal of Teacher Education, 39(8), 85-108.

Cuddapah, J. L., \& Clayton, C. D. (2011). Using Wenger's communities of practice to explore a new teacher cohort. Journal of Teacher Education, 62(1), 62-75.

Devos, A. (2010). New teachers, mentoring and the discursive formation of professional identity. Teaching and Teacher Education, 26(5), 1219-1223.

Fredericks, B. (2013). We don't leave our identities at the city limits': Aboriginal and Torres strait islander people living in urban localities. Australian Aboriginal Studies, 2013(1), 4-16.

Gay, G. (2010). Culturally responsive teaching: Theory, research, and practice. Teachers College Press.

Gillan, K., Mellor, S., \& Krakouer, J. (2017). The case for urgency: Advocating for Indigenous voice in education. ACER Press.

Harrison, H., Birks, M., Franklin, R., \& Mills, J. (2017). Case study research: Foundations and methodological orientations. Qualitative Social Research, 18(1), 1-12.

Harrison, N., Page, S., \& Tobin, L. (2016). Art has a place: Country as teacher in the city. Educational Philosophy and Theory, 48(13), 1321-1335.

Harwood, V., \& Murray, N. (2019). The promotion of education: A critical cultural social marketing approach. Springer International Publishing AG. https://doi.org/10.1007/978-3-030-25300-4

Hattie, J. (2009). Visible learning: A synthesis of over 800 meta-analyses relating to achievement. Routledge.

Kemmis, S., Heikkinen, H., Fransson, G., Aspors, J., \& Edwards-Groves, C. (2014). Mentoring of new teachers as a contested practice: Supervision, support and collaborative self-development. Teaching and Teacher Education, 43, 154-164.

Ladwig, J., Gore, J., Amosa, W., \& Griffiths, T. (2009). 'Quality teaching matters: A study investigating the links between quality teaching and improved student outcomes shows promising results for teaching and learning in NSW public schools' Side by Side. 27 August, p. 13

Lefstein, A., \& Snell, J. (2014). Better than best practice: Developing teaching and learning through dialogue. Routledge.

Lincoln, Y., Smith, L., \& Denzin, N. (2008). Introduction: Critical methodologies and indigenous inquiry. In N. K. Denzin, L. T. Smith, \& Y. S. Lincoln (Eds.), Handbook of critical and indigenous methodologies (pp. 1-28). Sage Publications.

Lopez, A. E. (2013). Collaborative mentorship: A mentoring approach to support and sustain teachers for equity and diversity. Mentoring \& Tutoring: Partnership in Learning, 21(3), 292-311.

Lowe, K., Harrison, N., Tennent, C., Guenther, J., Vass, G., \& Moodie, N. (2019a). Factors affecting the development of school and Aboriginal community engagement. A systematic review. Australian Educational Researcher, 46(2), 253-271. 
Lowe, K., Skrebneva, I., Burgess, C., Harrison, N., \& Vass, G. (2020). Towards an Australian model of culturally nourishing schooling. Journal of Curriculum Studies. https://doi.org/10.1080/00220272. 2020.1764111

Lowe, K., Tennent, C., Guenther, J., Harrison, N., Burgess, C., Moodie, N., \& Vass, G. (2019b). Aboriginal voices: Supporting the undertaking of concurrent systematic reviews of recent research literature in key areas of Aboriginal school education in Australia. The Australian Educational Researcher, 46(2), 213-229.

Ma Rhea, Z. (2015). Leading and managing Indigenous education in the postcolonial world. Routledge.

McKnight, A., Harwood, Priestly, A., \& Trindorfer, J. (2018). 'No shame at AIME': Listening to aboriginal philosophy and methodologies to theorise shame in educational contexts. The Australian Journal of Indigenous Education, 49(1), 46-56.

McMahon, S., Harwood, V., Bodkin-Andrews, G., O’Shea, S., McKnight, A., Chandler, P., \& Priestly, A. (2017). Lessons from the AIME approach to the teaching relationship: Valuing biepistemic practice. Pedagogy, Culture and Society, 25(1), 43-58.

Moodie, N. (2018). Decolonising race theory: Place, survivance and sovereignty. In G. Vass, J. Maxwell, S. Rudolph, \& K. N. Gulson (Eds.), The relationality of race in education research (pp. 33-46). Routledge.

Murray, N., \& Harwood, V. (2016). The importance of aboriginal protocols in promoting educational futures. National Centre for Student Equity in Higher Education.

Naylor, R., \& Sayed, Y. (2014). Teacher quality: Evidence review. Office of Development Effectiveness, Department of Foreign Affairs and Trade, Commonwealth of Australia.

Shay, M. (2019). Extending the yarning yarn: Collaborative yarning methodology for ethical indigenist education research. The Australian Journal of Indigenous Education. https://doi.org/10.1017/jie. 2018.25

Sinclair, K. (2020). Critical challenges of cultural competence professional development world. Journal of Educational Research, 7(1), 194-208.

Smith, L. T. (2012). Decolonizing methodologies: Research and indigenous peoples. Zed Books.

Tolbert, S. (2015). "Because they want to teach you about their culture": Analyzing effective mentoring conversations between culturally responsible mentors and secondary science teachers of Indigenous students in mainstream schools. Journal of Research in Science Teaching, 52(10), 1325-1361.

Vass, G., Lowe, K., Burgess, C., Harrison, N., \& Moodie, N. (2019). The possibilities and practicalities of professional learning in support of Indigenous student experiences in schooling: A systematic review. Australian Educational Researcher, 46(2), 341-361.

Ware, V. (2013). Mentoring programs for indigenous youth at-risk. Closing the gap clearinghouse resource sheets. 20. Australian Institute of Health and Welfare.

Yosso, T. J. (2005). Whose culture has capital? A critical race theory discussion of community cultural wealth. Race Ethnicity and Education, 8, 69-91.

Yunkaporta, T., \& McGinty, S. (2009). Reclaiming Aboriginal knowledge at the cultural interface. Australian Educational Researcher, 36(2), 55-72.

Zozakiewicz, C. (2010). Culturally responsible mentoring: Exploring the impact of an alternative approach for preparing student teachers for diversity. The Teacher Educator, 45(2), 137-151.

Publisher's Note Springer Nature remains neutral with regard to jurisdictional claims in published maps and institutional affiliations.

Cathie Burgess is an Associate Professor in Aboriginal Education, Aboriginal Studies teaching methods, Aboriginal Community Engagement and the Leadership in Aboriginal Education master's program. She has extensive teaching and leadership experience in secondary schools. Cathie's research involves community-led initiatives positioning Aboriginal community-based educators as leaders through a range of projects.

Valerie Harwood is a Professor of Sociology and Anthropology of Education and an Australian Research Council Future Fellow. Valerie's research is centred on a social and cultural analysis of participation in educational futures. This work involves learning about collaborative approaches and in-depth fieldwork on educational justice with young people, families and communities. 